\title{
Identification of Flow-units using Methods of Testerman Statistical Zonation, Flow Zone Index, and Cluster Analysis in Tabnaak Gas Field
}

\section{Mahjour SK ${ }^{1 *}$, Mohammad Kamal Ghasem Al-Askari² and Mohsen Masihi ${ }^{3}$}

${ }^{1}$ Department of Petroleum engineering, Science and Research branch, Islamic Azad University, Tehran, Iran ${ }^{2}$ Department of Petroleum Engineering, Petroleum University of Technology P. O. Box 63431, Ahwaz, Iran ${ }^{3}$ Department of Chemical and Petroleum Engineering, Sharif University of Technology, Tehran, I.R. Iran

\begin{abstract}
The relation between porosity and permeability parameters in carbonated rocks is complicated and indistinct. Flow units are defined with aim of better understanding reservoir unit flow behavior and relation between porosity and permeability. Flow-units reflect a group of rocks with same geological and physical properties which affect fluid flow, but they do not necessarily coincide with boundary of facies. In each flow-unit homogeneity of data preserved and this homogeneity fades in the boundaries. Here in this study three methods are used for identification of flowunits and estimation of average porosity and permeability in three wells of Tabnaak gas field located in south of Iran. These methods include Testerman statistical zonation, flow zone index (FZI), and cluster Analysis. To identify these units, compilation of core porosity and permeability are used. After comparing results of flow units developed by these three methods, a good accordance in permeable zones obtained for them, but for general evaluation of flowunits in field scale, the methods of $\mathrm{FZl}$ and cluster analysis are more relevant than Testerman statistical zonation.
\end{abstract}

Keywords: Flow-Unit; Flow Zone Index; Cluster Analysis; Testerman Statistical Zonation; Porosity; Permeability

\section{Introduction}

Interpreting reservoir parameters are important and indispensable for development of oil and gas fields. Because of getting better perception about reserves and flow properties from hydrocarbon reservoirs and being a base for reservoir simulators, methods of interpreting reservoir parameters are valuable. Different methods result in description of hydrocarbon formation in different scales according to segregation ability, covering and number of measured parameters.

Many efforts had been taken to relate reservoir parameters and one of them is to relate porosity and permeability, so complexity of carbonated rock pore spaces always was very problematic.

Investigators tried to find a logical relation between these two vital parameters in hydrocarbon reservoirs. Assigning flow-units is one of presented techniques that help to recognize permeable reservoir zones and relations of porosity and permeability.

Flow-unit is a method for classification of rock types in pore scale according to flow properties based on geological parameters and physics of flow. These units are sections of the whole reservoir which have constant geological and petrophysical properties that affect fluid flow, and are different from other sections obviously [1]. Subsurface and surface studies had shown that fluid flow-units are not always coincident with geological boundary. The concept of flow-unit is a strong and peculiar tool for dividing reservoir into units which estimate inter-structure of reservoir in a compatible scale for reservoir simulation models [1].

Permeability and porosity of reservoir rock considered as the most important parameters for evaluation and estimation of reservoir [2]. Besides, porosity vs. permeability diagrams has overmuch scattering and a weak correlation in heterogeneous carbonated reservoirs. Therefore, there is not any specific relation between these two.

Notwithstanding a close relation between porosity and permeability can't be observed in a well, but with classifying and sorting data according to hydraulic flow-units, a better zonation can be achieved. Considering the purpose, the selected scale, and available data, different ways exist for determination of flow-units.

In this study, flow-units identification methods are used based on Testerman statistical zonation [3], flow zone index (FZI) [4] and cluster analysis [5] and comparing these methods is done for three wells in Tabnak gas field.

\section{Geology of studied Location}

According to Oil and Gas journal of national Iranian oil Company (NIOC) [6], sweet gas field of Tabnaak was discovered in year 2000. Tabnaak field is the largest onshore sweet gas field in Iran. This field is located in south of Iran, in south-west of Lamerd, in east side of Asalouyeh anticline. Hydrocarbon containing strata's in this field are Dashtak, Kangaan, and upper Dalaan. Figure 1 shows position of Tabnaak gas field.

\section{Data and Methods}

In this study three methods are used for identification of flow units by using core data from three drilled wells in subsurface strata's of Tabnaak gas field. Position of these wells indicated in Figure 2. Here we studied following methods.

*Corresponding author: Mahjour SK, Department of Petroleum engineering Science and Research branch, Islamic Azad University, Tehran, Iran, Tel: +989362975949; E-mail: mahjourpetroleum@yahoo.com

Receive September 09, 2015; Accepted October 29, 2015; Published November 11, 2015

Citation: Mahjour SK, Al-Askari MKG, Masihi M (2015) Identification of Flow-units using Methods of Testerman Statistical Zonation, Flow Zone Index, and Cluster Analysis in Tabnaak Gas Field. J Pet Environ Biotechnol 6: 253. doi:10.4172/21577463.1000253

Copyright: (C) 2015 Mahjour SK, et al. This is an open-access article distributed under the terms of the Creative Commons Attribution License, which permits unrestricted use, distribution, and reproduction in any medium, provided the original author and source are credited. 


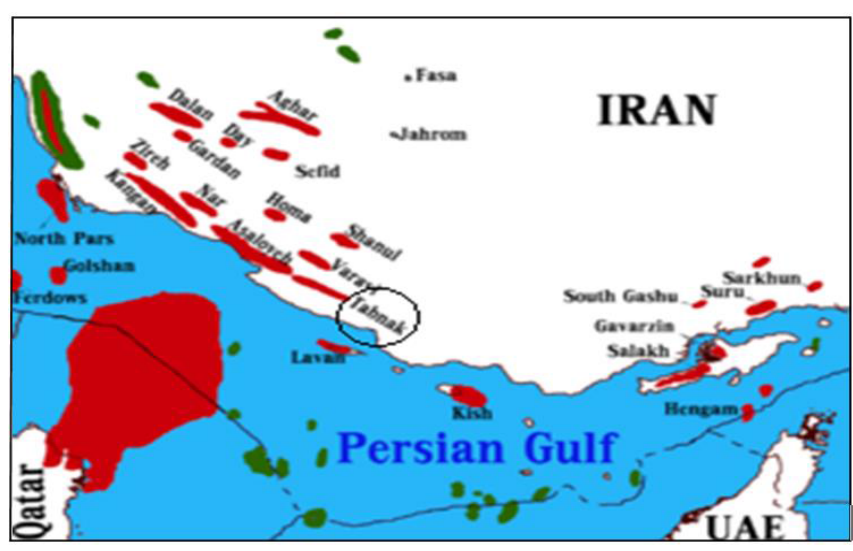

Figure 1: Tabnaak gas field position [14].

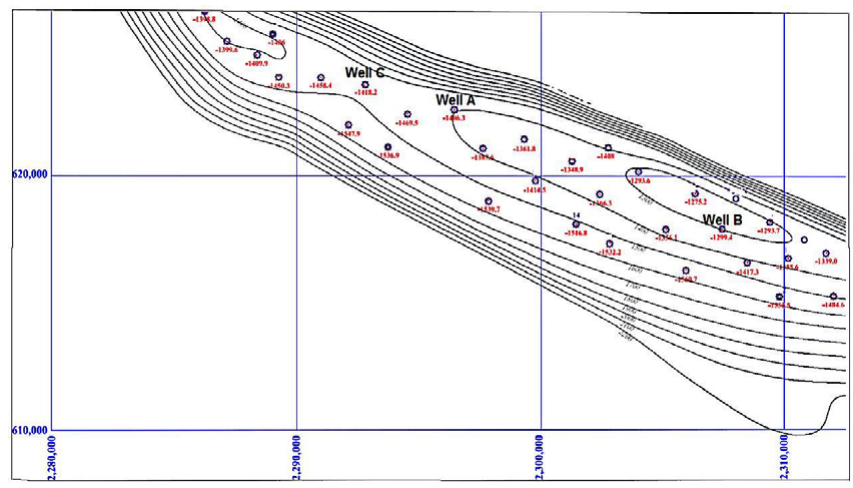

Figure 2: Position of wells [14]

\section{Introducing Flow-Units Using Testerman Statistical Zonation Method}

Statistical Zonation came into attention after presenting the concept of flow-unit. This method which was presented by Testerman, doesn't need any prejudgment about number of zones and also the number of zone boundaries are controlled automatically and by predefinition of an ending condition. In Testerman method zonation is done only by using core permeability data. Testerman method is applied in two steps. These steps are:

Identification of flow-units separately;

Assessing continuity of flow-units in adjacent wells.

In the first step each well separately divided into zones or flow-units. These zones selected in a manner that the variance of quantities in each zone is minimum, and the variance between zones be as maximum as possible. This method uses zonation coefficient " $R$ " as a criterion for zonation. Equations (1), (2), and (3) applied for zonation of each well:

$$
\begin{aligned}
& B=\frac{1}{L-1}\left[\sum_{i=1}^{l} m_{i}\left(\overline{k_{i .}}-\bar{k} . .\right)^{2}\right] \\
& W=\frac{1}{N-1}\left[\sum_{i=1}^{L} \sum_{j=1}^{m_{i}}\left(\overline{k_{i j}}-\overline{k_{i .}}\right)^{2}\right]
\end{aligned}
$$

$$
R=\frac{B-W}{B}
$$

Where:

B: Variance between zones

L: $\quad$ Number of Zones

W: Variance in each zone

$\mathrm{m}_{\mathrm{i}}$ : Number of permeability data in $\mathrm{i}^{\text {th }}$ zone

$\mathrm{j}$ : Index for algebraically summation of data of each zone

i: Index for algebraically summation of zones

$\mathrm{N}$ : Number of total permeability data of reservoir

$\mathrm{k}_{\mathrm{ij}}$ : Permeability data of network $(\mathrm{mD})$

R: Zonation Coefficient

$\bar{k}$ : Summation of average permeability data in well $(\mathrm{mD})$

$\overline{k_{i}}$ : Average permeability data in $\mathrm{i}^{\text {th }}$ zone $(\mathrm{mD})$

The coefficient " $R$ " which is the best criterion for zone segregation has a value between zero and one; more it's value close to one, the zones are more homogeneous. According to its definition, it can't occupy a negative value and the negative values should be replaced by zero.

In separately zonation of each well, First of all permeability data in each depth should be identified. This process begins with first sample from to highest depth and proceeds to lowest depth and then the zonation coefficient of each zone is calculated by equations (1) to (3). Actually this coefficient indicates that how much homogeneously this zonation divides the zones. The more this coefficient close to one the more the zones are homogeneous. Therefor the largest zonation coefficient obtains the most suitable zonation of well into two zones.

Then these steps repeat separately for each of two segregated zones. Division of zones proceeds until the yielding zonation coefficient in the next step becomes less than the previous.

After identification of flow-units for each well the second part of calculations starts. This section interrelates the flow-units in territory of reservoir from one well to another well for determination of flow-units continuity. Calculations are done based on a statistical comprising of difference between average data in adjacent well zones, and the difference which is expected from measurement of variance values in zones. Mathematical expression for this phrase presented by equation (4):

$$
\left(\overline{k_{h .}}-\overline{k_{i .}}\right)>\sqrt{\frac{1}{2}\left(\frac{1}{n_{h}}+\frac{1}{n_{i}}\right)} S z_{(v, p)}
$$

Where:

$\overline{k_{h}}$ : Arithmetic average of permeability data for $\mathrm{h}^{\text {th }}$ zone in a well

$\overline{k_{i}}$ : Arithmetic average of permeability data for $\mathrm{i}^{\text {th }}$ zone in adjacent well

$\mathrm{n}_{\mathrm{i}} \& \mathrm{n}_{\mathrm{h}}$ : Number of data for $\mathrm{h}^{\text {th }}$ and $\mathrm{i}^{\text {th }}$ zones

s: $\quad$ Standard deviation of total permeability data of reservoir

z: Tabulated constant as a function of data, number of zones and probability level

$\mathrm{v}, \mathrm{p}$ : Used for identifying $\mathrm{z}$ as a function of probability level 
"Z" values are presented in Harter [7] table. If left side of equation be more than the right side, according to statistics, zones are differed from each other, and if the left side of equation be less than the right side, zones are related and continuous.

According to copious amounts of data and for attaining optimum zonation, hand calculation isn't possible or at least faces with numerous problems therefor for simplicity of operation and fast zonation, composing program code for calculations is inevitable. This code is composed in Matlab $^{\star}$ software. Because of limitation in composing all the calculations, in this paper we choose to only mention outputs of well $\mathrm{A}$ as an instance. Table 1 shows permeability data and similar depths and Table 2 shows division of permeability data into three zones for well A. Equations (2) to (4) used for calculation of variance between zones, variance in each zone, and zonation coefficient, respectively. " $R$ " values in some points are negative which is substituted by zero for compatibility with its definition. As shown in Table 2 first step indicates zonation of well into two zones which maximum value of R in boundary of zones is equal to 0.884265 . In second step, data divided into two groups and again using equations (2) to (4) value of $\mathrm{R}$ for each group is calculated. Though maximum value for group one was 0.809522 but because it is less than 0.884265 the closing condition executed and dose not divides into groups anymore. But the maximum $\mathrm{R}$ for group two is 0.961796 which is more than 0.884265 , so group two with coefficient of 0.961796 divides into another two zones. In third step, maximum $\mathrm{R}$ is less than 0.961796 so the closing condition executed and well $\mathrm{A}$ segregates into three zones. Table 3-5 shows statistical indexes of core permeability data in three wells.

After all wells zoned separately, assessment of continuity of wells is done using equation (5). This showed that the introduced zones in the interval of three studied wells are developed and continuous. Figure 3 shows cross section of three wells which indicates continuity of three adjacent wells with each other.

\section{Flow Zone Index (FZI) Method}

Flow-units (hydraulic) are identified based on FZI In this method, which is product of dividing Reservoir quality index (RQI) by normalized porosity $\left(\varphi_{z}\right)$ [4]. Reservoir quality grows with produced number. RQI is an approximation of average hydraulic radius in reservoir rock and a key for hydraulic-units and correlate between porosity, permeability and capillary pressure [8]. FZI is also function of pore throat, tortuosity, and effective area based on texture properties, sedimentation model, pore geometry, and digenesis effects [9]. Values of reservoir quality index, normalized porosity, and flow zone can be calculated by these equations.

$$
\begin{aligned}
& R Q I=0.0314 \sqrt{\frac{k}{\varphi_{e}}} \\
& \varphi_{z}=\frac{\varphi_{e}}{1-\varphi_{e}} \\
& F Z I=R Q I /\left(\varphi_{z}\right)
\end{aligned}
$$

Permeability $(\mathrm{K})$ in above equations is in $\mathrm{mD}$ and $\varphi_{\mathrm{e}}$ is a fraction. By taking logarithm of two sides of equation (7) we can write:

$$
\log (R Q I)=\log \left(\varphi_{z}\right)+\log (F Z I)
$$

Equation (8) presents a straight line with slope of unity in RQI vs, $\varphi_{z}$ diagram. Intersection of this straight line in $\varphi_{z}$ equal to one is the flow zone index. Samples which are on a straight line happen to have similar properties and so contribute to make a flow-unit. Straight lines with slope of unity are firstly expected for non-shale containing sandstone formation. Larger slopes identify shale formations. Rocks with detrital material have porous stratification, filling and fine grains generally therefor they indicate low amounts of FZI. In opposite, sands which have low amount of shale, large and sorted grains, low shape factor, and low tortuosity, indicate large FZI. Different sedimentation environments, digenesis processes and reservoir geometry are controlling parameters for FZI [10].

There are different ways for zonation and identification of hydraulic flow-units by using flow zone index; including histogram analysis, probability diagram, and analytic classification algorithm. Graphical classification methods which include histogram analysis and probability diagram indicate FZI distribution visually, which makes it possible to define hydraulic flow-units. Method which is used in this paper is "normal probability" [11]. The number of break points or deviations in this diagram puts the number of hydraulic flow-units in. Because of vast FZI changes there is used the logarithmic value. Figures 4-6 show normal probability diagrams and hydraulic flow-units for

\begin{tabular}{|c|c|c|c|c|c|}
\hline Thickness (m) & Permeability (mD) & Thickness (m) & Permeability (mD) & Thickness (m) & Permeability (mD) \\
\hline 2642.18 & 0.87 & 2646.9 & 3.5 & 2649.01 & 4.47 \\
\hline 2642.25 & 0.87 & 2647.02 & 0.74 & 2649.35 & 15.63 \\
\hline 2642.45 & 0.87 & 2647.37 & 1.64 & 2649.42 & 17.93 \\
\hline 2643.97 & 0.34 & 2647.43 & 1.75 & 2649.64 & 8.73 \\
\hline 2644.05 & 0.5 & 2647.53 & 4.16 & 2649.73 & 4.97 \\
\hline 2645.92 & 4.26 & 2647.8 & 0.89 & 2649.84 & 2.28 \\
\hline 2645.99 & 4.59 & 2647.87 & 1.68 & 2649.91 & 2.14 \\
\hline 2646.2 & 5.61 & 2647.98 & 2.92 & 2650.3 & 1.4 \\
\hline 2646.27 & 6.96 & 2648.06 & 2.32 & 2650.36 & 1.47 \\
\hline 2646.37 & 3.49 & 2648.24 & 0.99 & 2650.96 & 2.16 \\
\hline 2646.43 & 1.4 & 2648.5 & 0.55 & ---- & ---- \\
\hline 2646.63 & 2.65 & 2648.77 & 1.86 & --- & --- \\
\hline 2646.7 & 3.39 & 2648.83 & 2.27 & --- & --- \\
\hline 2646.84 & 4.88 & 2648.92 & 2.9 & --- & --- \\
\hline
\end{tabular}
wells A, B, and C, respectively. These are plotted with Minitab ${ }^{\circ}$ software.

Flow zone index does not necessarily depend on facies and different facies can be placed in one specific hydraulic flow-unit.

Table 1: Permeability data of well A. 
Citation: Mahjour SK, Al-Askari MKG, Masihi M (2015) Identification of Flow-units using Methods of Testerman Statistical Zonation, Flow Zone Index, and Cluster Analysis in Tabnaak Gas Field. J Pet Environ Biotechnol 6: 253. doi:10.4172/2157-7463.1000253

Page 4 of 13

\begin{tabular}{|c|c|c|c|c|c|c|c|c|c|}
\hline \multirow[b]{2}{*}{ Depth point } & \multicolumn{3}{|c|}{ First step } & \multicolumn{3}{|c|}{ Second step } & \multicolumn{3}{|c|}{ Third step } \\
\hline & B & W & $\mathrm{R}$ & B & W & $\mathrm{R}$ & B & W & $\mathrm{R}$ \\
\hline & Group1 & & Group1 & Group1 & & Group1 & Group1 & & Group1 \\
\hline 1 & 6.656 & 13.991 & 0 & 50.688 & 11.684 & 0.769477 & 102.818 & 5.938 & 0.942247 \\
\hline 2 & 13.696 & 13.795 & 0 & 52.091 & 11.604 & 0.777222 & 103.753 & 5.8555 & 0.943563 \\
\hline 3 & 21.162 & 13.588 & 0.357881 & 53.613 & 11.517 & 0.785169 & 104.768 & 5.766 & 0.944964 \\
\hline 4 & 32.159 & 13.283 & 0.586958 & 56.281 & 11.365 & 0.798064 & 106.547 & 5.6090 & 0.947356 \\
\hline 5 & 42.906 & 12.984 & 0.697375 & 58.886 & 11.21 & 0.809522 & 108.283 & 5.455 & 0.949615 \\
\hline 6 & 32.499 & 13.273 & 0.591575 & 54.637 & 11.459 & 0.790264 & 105.450 & 5.7058 & 0.945891 \\
\hline 7 & 23.734 & 13.517 & 0.430478 & 51.674 & 11.628 & 0.774965 & 103.47 & 5.880 & 0.943174 \\
\hline 8 & 14.160 & 13.783 & 0.026651 & 49.658 & 11.743 & 0.763507 & 102.131 & 5.9986 & 0.941265 \\
\hline 9 & 5.1060 & 14.034 & 0 & 50.009 & 11.723 & 0.765571 & 102.36 & 5.9780 & 0.941601 \\
\hline 10 & 4.6549 & 14.047 & 0 & 50.501 & 11.695 & 0.768408 & 102.693 & 5.9491 & 0.942069 \\
\hline 11 & 7.9300 & 13.956 & 0 & 49.947 & 11.727 & 0.765205 & 102.324 & 5.9817 & 0.941542 \\
\hline 12 & 9.0973 & 13.923 & 0 & 50.012 & 11.72 & 0.765586 & 102.367 & 5.9778 & 0.941604 \\
\hline 13 & 8.78 & 13.932 & 0 & 50.458 & 11.698 & 0.768163 & 102.665 & 5.9516 & 0.942029 \\
\hline 14 & 5.8808 & 14.013 & 0 & 52.206 & 11.598 & 0.777838 & 103.830 & 5.8488 & 0.94367 \\
\hline 15 & 5.6058 & 14.020 & 0 & 53.236 & 11.539 & 0.783243 & 104.517 & 5.7882 & 0.944619 \\
\hline 16 & 10.408 & 13.887 & 0 & 51.675 & 11.628 & 0.774968 & 103.476 & 5.8800 & 0.943175 \\
\hline 17 & 14.419 & 13.775 & 0.044646 & 51.073 & 11.662 & 0.771643 & 103.075 & 5.9154 & 0.94261 \\
\hline 18 & 18.700 & 13.656 & 0.269691 & 50.656 & 11.686 & 0.769291 & 102.796 & 5.9400 & 0.942216 \\
\hline 19 & 16.645 & 13.714 & 0.17613 & 52.080 & 11.605 & 0.777164 & 103.746 & 5.8562 & 0.943553 \\
\hline 20 & 24.10 & 13.506 & 0.439555 & 50.905 & 11.672 & 0.7707 & 102.96 & 5.9253 & 0.942452 \\
\hline 21 & 30.240 & 13.33 & 0.558988 & 50.478 & 11.696 & 0.768275 & 102.678 & 5.9504 & 0.942047 \\
\hline 22 & 32.529 & 13.27 & 0.591981 & 50.953 & 11.669 & 0.770972 & 102.995 & 5.9224 & 0.942497 \\
\hline 23 & 37.511 & 13.134 & 0.649856 & 51.063 & 11.663 & 0.771587 & 103.068 & 5.9160 & 0.942601 \\
\hline 24 & 49.31 & 12.806 & 0.740313 & 50.124 & 11.71 & 0.766237 & 102.442 & 5.971 & 0.941711 \\
\hline 25 & 65.949 & 12.344 & 0.812818 & 49.41 & 11.75 & 0.762044 & 101.967 & 6.0131 & 0.941029 \\
\hline 26 & 78.042 & 12.008 & 0.846128 & 49.409 & 11.758 & 0.762026 & 101.96 & 6.0133 & 0.941026 \\
\hline 27 & 89.576 & 11.688 & 0.869517 & 49.492 & 11.753 & 0.762526 & 102.021 & 6.0084 & 0.941106 \\
\hline 28 & 98.781 & 11.432 & 0.884265 & Group2 & 11.759 & Group2 & Group2 & 6.014 & Group2 \\
\hline 29 & 97.858 & 11.458 & 0.882911 & 50.892 & 11.673 & 0.770631 & 125.10 & 3.9714 & 0.958256 \\
\hline 30 & 29.77 & 13.349 & 0.551646 & 68.746 & 10.653 & 0.845038 & 105.531 & 5.6986 & 0.946 \\
\hline 31 & 0.1112 & 14.173 & 0 & 141.6 & 6.4885 & 0.954185 & 105.853 & 5.6703 & 0.946432 \\
\hline 32 & 7.3786 & 13.971 & 0 & 152.92 & 5.8425 & 0.961796 & Group3 & 6.0144 & Group3 \\
\hline 33 & 13.483 & 13.801 & 0 & 138.77 & 6.651 & 0.952074 & 104.581 & 5.7825 & 0.944708 \\
\hline 34 & 11.829 & 13.847 & 0 & 111.72 & 8.196 & 0.926636 & 103.436 & 5.8835 & 0.94312 \\
\hline 35 & 9.895 & 13.901 & 0 & 91.650 & 9.344 & 0.898045 & 103.005 & 5.9215 & 0.942512 \\
\hline 36 & 5.4480 & 14.025 & 0 & 72.549 & 10.435 & 0.856158 & 102.3 & 5.983 & 0.941507 \\
\hline 37 & 1.6435 & 14.13 & 0 & 58.115 & 11.260 & 0.806239 & 101.977 & 6.0122 & 0.941043 \\
\hline 38 & 0 & 0 & 0 & 0 & 0 & 0 & 0 & 0 & 0 \\
\hline
\end{tabular}

Table 2: Zoned data of well A.

\begin{tabular}{|l|c|c|c|c|c|c|c|c|}
\hline & Number of Data & Min. & Max. & Arithmetic mean & Geometric mean & Harmonic mean & Variance & \\
\hline Deviation
\end{tabular}

Table 3: Zonation yielded by core permeability data in well A.

\begin{tabular}{|l|c|c|c|c|c|c|c|c|}
\hline & Number of Data & Min. & Max. & Arithmetic mean & Geometric mean & Harmonic mean & Variance & Standard \\
Deviation
\end{tabular}

Table 4: Zonation yielded by core permeability data in well $\mathrm{B}$. 
Citation: Mahjour SK, Al-Askari MKG, Masihi M (2015) Identification of Flow-units using Methods of Testerman Statistical Zonation, Flow Zone Index, and Cluster Analysis in Tabnaak Gas Field. J Pet Environ Biotechnol 6: 253. doi:10.4172/2157-7463.1000253

Page 5 of 13

\begin{tabular}{|l|c|c|c|c|c|c|c|c|}
\hline & Number of Data & Min. & Max. & Arithmetic mean & Geometric mean & Harmonic mean & Variance & Standard \\
Deviation
\end{tabular}

Table 5: Zonation yielded by core permeability data in well C.

\begin{tabular}{|l|c|c|c|c|c|c|c|}
\hline & Number of Data & Min. & Max. & Arithmetic mean & Geometric mean & Harmonic mean & Variance \\
\hline HFU1 & 14 & 0.557 & 17.935 & 5.54 & 3.95 & 2.70 \\
\hline HFU2 & 6 & 0.343 & 6.960 & 3.63 & 2.20 & 26.38 \\
\hline HFU3 & 8 & 1.408 & 4.160 & 2.40 & 2.28 & 2.13 & 2.17 \\
\hline HFU4 & 10 & 0.740 & 1.680 & 1.14 & 1.09 & 05 & 1.05 \\
\hline
\end{tabular}

Table 6: Statistical indexes of hydraulic flow-units of well A.

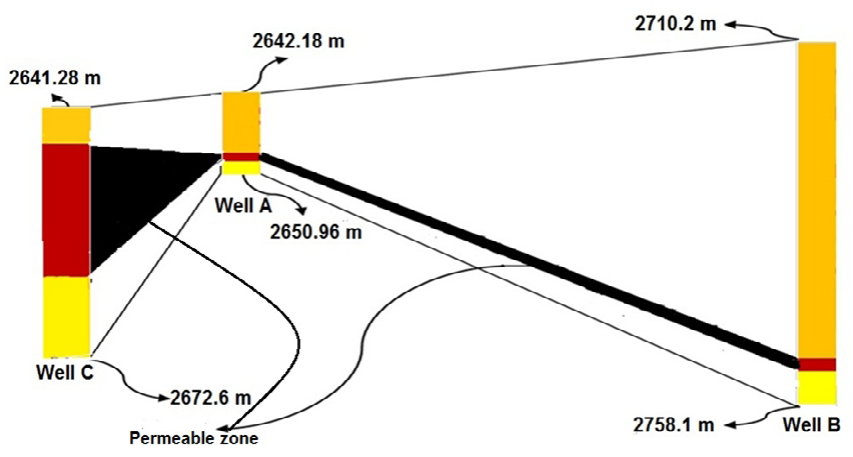

Figure 3: Cross section of Zonation of studied wells using Testerman method.

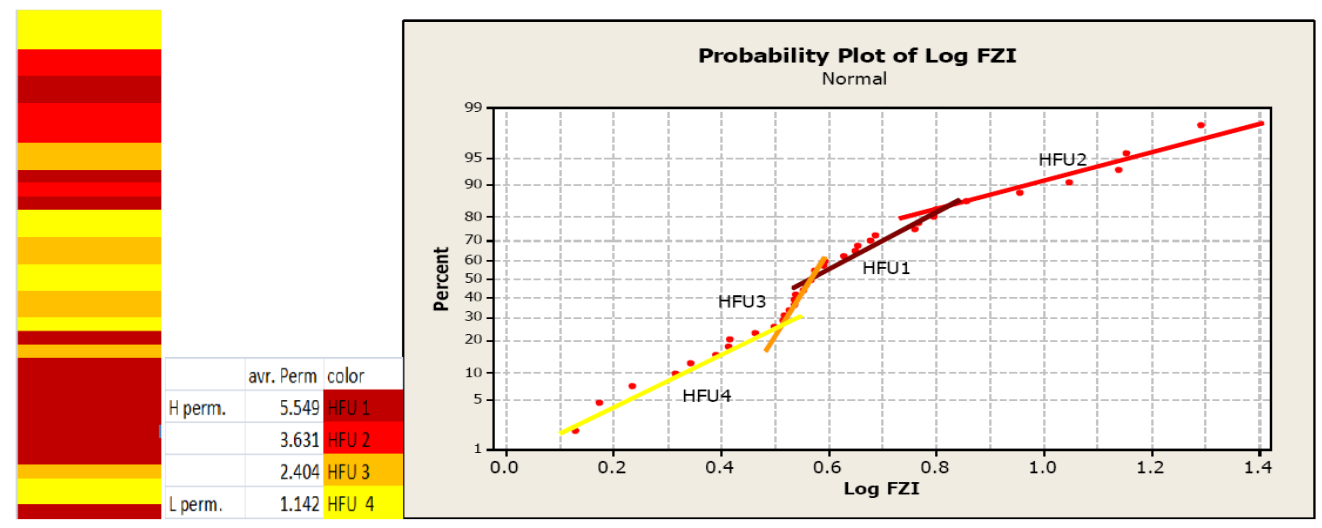

Well A

Figure 4: Normal probability diagram for well A.

According to three above plots it is obvious that the well A, B and $\mathrm{C}$ each one is constituted of four, five, and seven hydraulic flow-units, respectively. Logarithmic plot of RQI vs. $\varphi_{\mathrm{z}}$ is linear with slop of 45 degrees, in an ideal condition, and each line presents a hydraulic flowunit. The points which lines meet $\varphi_{\mathrm{z}}=1$ is the average FZI for respective hydraulic unit. Average FZI is useful for estimating permeability of the wells which have no cores. Relation between $\log$ RQI and $\varphi_{z}$ for each well is indicated in Figure 7.

Tables 6-8 show Statistical permeability indexes of hydraulic flowunits of wells $\mathrm{A}, \mathrm{B}$, and $\mathrm{C}$, respectively.

\section{Cluster analysis method}

Cluster analysis method has been used for accurate segregation of data and identification of rock groups. The purpose of cluster analysis is to put a set of data in one group (known as clusters) in a manner that the data in one group have no severe differences and be homogeneous and inhomogeneous relative to other groups [5]. Cluster analysis puts the data in groups which are meaningful, beneficial, or both of meaningful and beneficial [12]. Maximum analogy (homogeneity) in a group and dissimilarity between groups implies optimum clustering [12]. "Hierarchical clustering" is a method for contemporaneous 


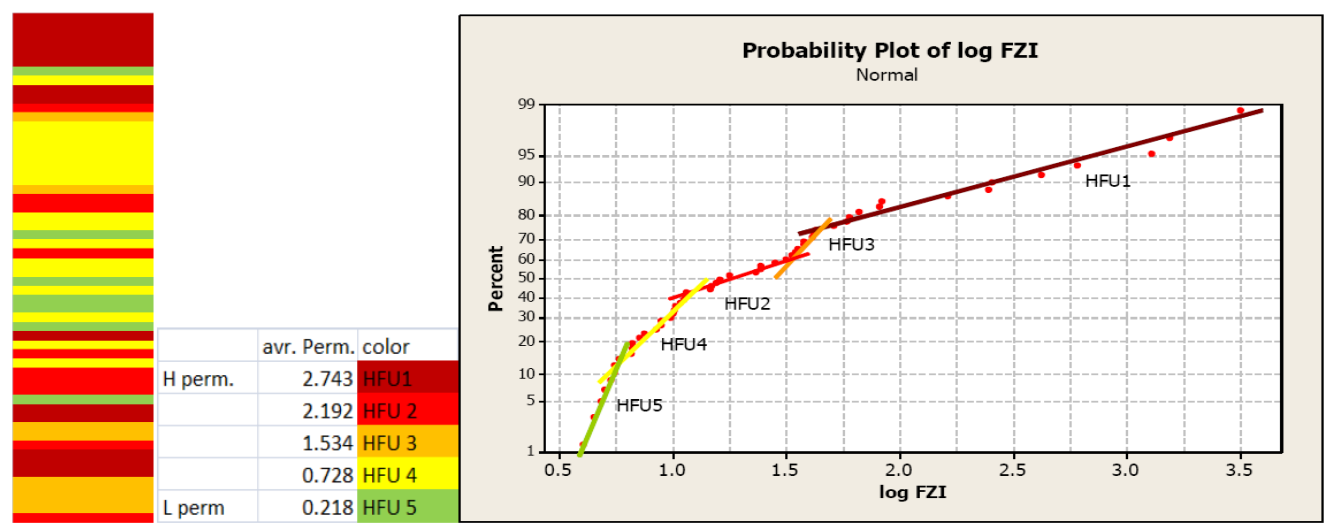

Well B

Figure 5: Normal probability diagram for well B.
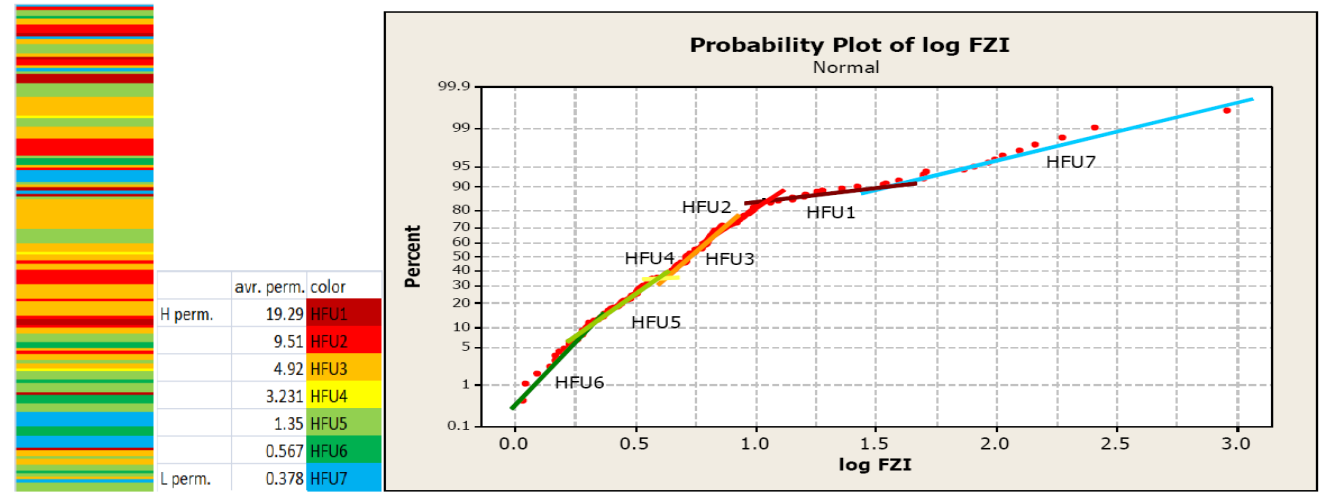

Well C

Figure 6: Normal probability diagram for well C.

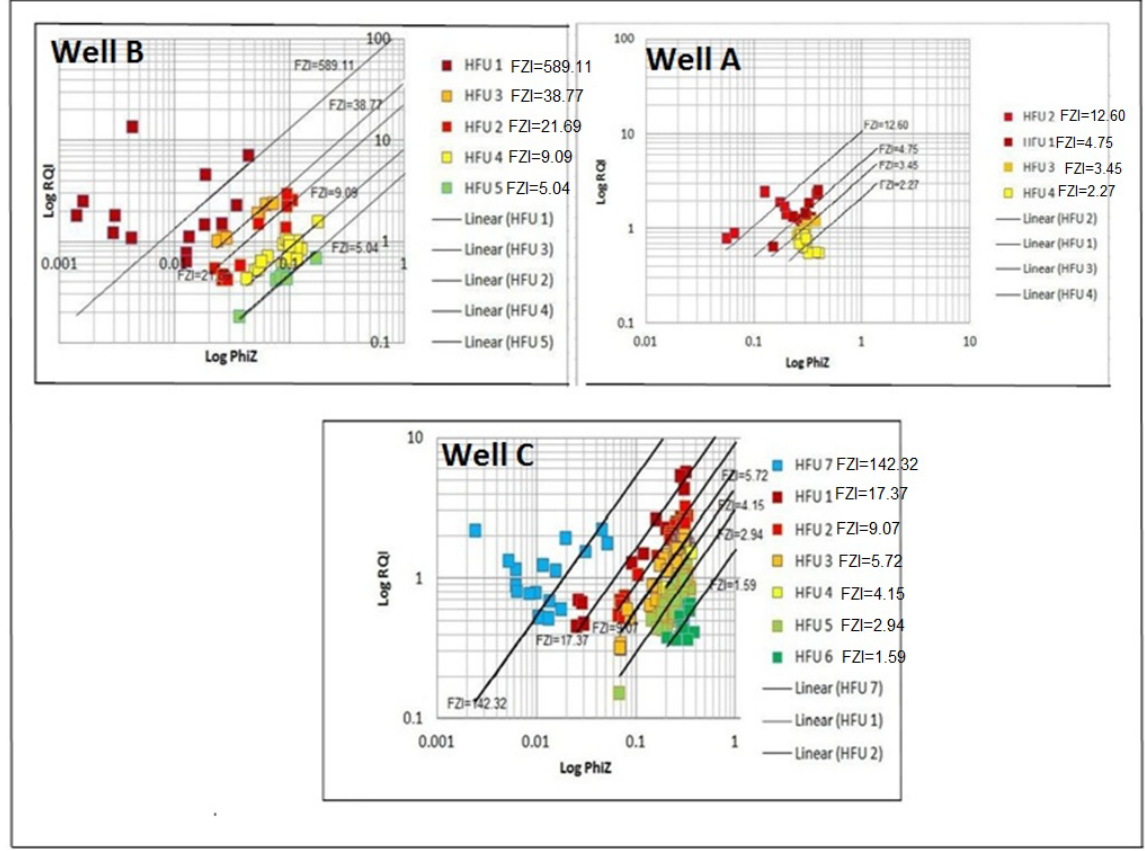

Figure 7: Relation between log RQI and $\varphi_{z}$ 
Citation: Mahjour SK, Al-Askari MKG, Masihi M (2015) Identification of Flow-units using Methods of Testerman Statistical Zonation, Flow Zone Index, and Cluster Analysis in Tabnaak Gas Field. J Pet Environ Biotechnol 6: 253. doi:10.4172/2157-7463.1000253

Page 7 of 13

\begin{tabular}{|l|c|c|c|c|c|c|c|c|}
\hline & Number of Data & Min. & Max. & Arithmetic mean & Geometric mean & Harmonic mean & Variance & Standard \\
Deviation
\end{tabular}

Table 7: Statistical indexes of hydraulic flow-units of well B.

\begin{tabular}{|l|c|c|c|c|c|c|c|c|}
\hline & Number of Data & Min. & Max. & Arithmetic mean & Geometric mean & Harmonic mean & Variance & Standard \\
Deviation
\end{tabular}

Table 8: Statistical indexes of hydraulic flow-units of well C.

grouping of data in different scales by clustered tree (dendriform). Output of this method is a graphical plot which is so called dendrigram or tree (dendriform), as it indicates structure of hierarchical clustering [13]. This tree isn't a set of independent data; rather it is a multilevel classification which the clusters in lower level rendered to upper levels [5]. This virtue allows us to choose which level or scale of clustering is more proper for the subject.

Hierarchical clustering analysis takes place in four steps which are: a) Calculating input vectors interspace. b) Establishment of parts related to interspacing's. c) Creating cluster tree. d) Creating Clusters.

Calculating Input Vectors Interspace: Spacing between data variables is calculated in this step. For achieving this there are many functions available. One prevalent method used for input vector interspacing calculation or, as we can say interspace between every pair of data, is calculating Euclidean interspace between data which is defined as summation of difference between all data or variables [14]. If we had two pairs of data $\left(x_{1}, y_{1}\right)$ and $\left(x_{2}, y_{2}\right)$ Euclidean interspace calculated by bellow formula:

Euclidean interspace $=\sqrt{\left(x_{2}-x_{1}\right)^{2}+\left(y_{2}-y_{1}\right)^{2}}$

Using equation (9) Euclidean interspace calculated between all pairs of data.

Establishment of Parts Related to Spacing's: In this step it should be determined that which one of created pairs of data should be placed in one cluster. Different methods exist for relating data and grouping them which here the method of least squares between clusters (wards) is used.

Creating Cluster Tree: The cluster tree forms in this step by using information yielded from degree of relation between data which places them in respected groups. Cluster tree is constituted by different sets of clusters, as each one of clusters is related to another cluster. In this kind of tree Horizontal axis includes number of data and vertical axis shows the amount which different clusters associate with each other to form new clusters. There are different methods for creating cluster tree but in this study the method of "Agglomerative Hierarchical Clustering" is used $[15,16]$. This method of clustering points out a series of clustering techniques with close relationship that each point considered as a discrete cluster in them and repeatedly combines two cluster which are close to each other (according to interspacing); therefor this method requires to define "proximity cluster" concept. Actually in cluster analysis calculation of proximity of two clusters is a key operation which is called proximity cluster. Amounts of minimum, maximum, and group average interspace are used for calculation of proximity cluster [17].

Creating Clusters: After creating cluster tree by definition of a special level called "cut off" we can introduce arbitrary large or small clusters. It is so important to select the foremost and proper number of plotted clusters; as the number of plotted clusters which entirely establish a cluster tree, should reflect the most proper types of rock for carbonated rocks [18].

Here in this study the cluster tree is plotted and number of clusters for each well identified based on hydraulic flow-units using Minitab * According to this, clusters of wells A, B and C are equal to (4), (5) and (7) respectively. Figures 8-10 shows dendrigram plot of three wells.

Tables 9-11 show statistical permeability index of wells A, B, and C respectively.

\section{Results}

\section{Investigating Relation between Porosity and Permeability in Flow-Units}

Though formations generally interpreted as uniform and homogeneous, but there is no specific relation between porosity and permeability. In the studied field the sedimentary environment, geological parameters, and rock nature cause to creation of geological complex and heterogeneous reservoirs. Then as we can see in Figure 11 there is no meaningful correlation between porosity and permeability in studied well and a weak correlation coefficient $\left(\mathrm{R}^{2}\right)$ stands for these two parameters. In this section we are attended to understand that if grouping permeability and porosity data could provide a specific relation for these two petrophysical parameters. Equipping a specific relation between porosity and permeability can be helpful for estimating permeability between wells. 
Citation: Mahjour SK, Al-Askari MKG, Masihi M (2015) Identification of Flow-units using Methods of Testerman Statistical Zonation, Flow Zone Index, and Cluster Analysis in Tabnaak Gas Field. J Pet Environ Biotechnol 6: 253. doi:10.4172/2157-7463.1000253

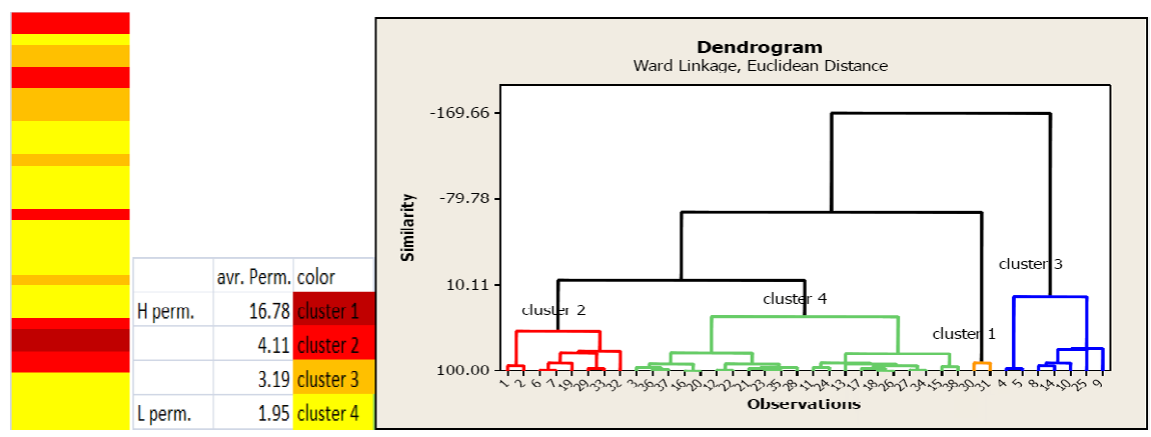

Well A

Figure 8: Dendrigram plot of well A using cluster analysis method.

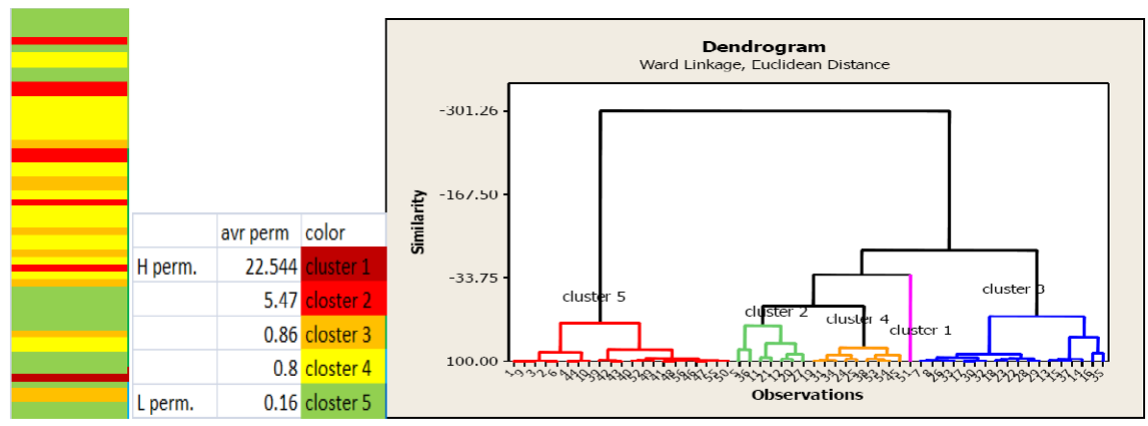

Well B

Figure 9: Dendrigram plot of well B using cluster analysis method.

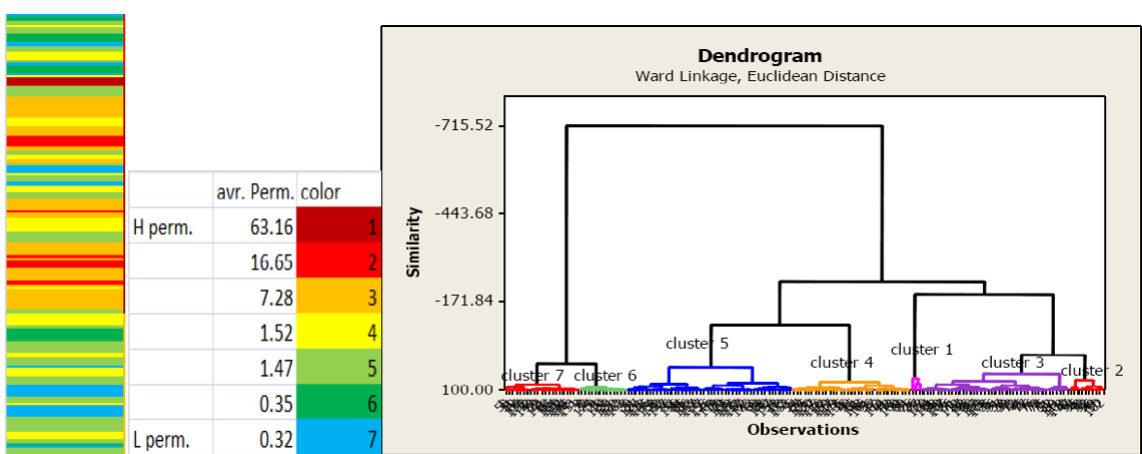

Well C

Figure 10: Dendrigram plot of well C using cluster analysis method.

\begin{tabular}{|l|c|c|c|c|c|c|c|}
\hline & Number of Data & Min. & Max. & Arithmetic mean & Geometric mean & Harmonic mean & Variance \\
Deviation
\end{tabular}

Table 9: Statistical permeability index yielded by cluster analysis in well A. 
Citation: Mahjour SK, Al-Askari MKG, Masihi M (2015) Identification of Flow-units using Methods of Testerman Statistical Zonation, Flow Zone Index, and Cluster Analysis in Tabnaak Gas Field. J Pet Environ Biotechnol 6: 253. doi:10.4172/2157-7463.1000253

Page 9 of 13

\begin{tabular}{|c|c|c|c|c|c|c|c|c|}
\hline & Number of Data & Min. & Max. & Arithmetic mean & Geometric mean & Harmonic mean & Variance & $\begin{array}{l}\text { Standard } \\
\text { Deviation }\end{array}$ \\
\hline Cluster1 & 1 & 22.544 & 22.544 & 22.544 & 22.544 & 22.544 & ----- & ----- \\
\hline Cluster2 & 7 & 3.288 & 8.400 & 5.47 & 5.15 & 4.87 & 4.26 & 2.06 \\
\hline Cluster3 & 9 & 0.129 & 1.970 & 0.86 & 0.48 & 0.28 & 0.68 & 0.82 \\
\hline Cluster4 & 18 & 0.162 & 3.794 & 0.80 & 0.55 & 0.40 & 0.71 & 0.79 \\
\hline Cluster5 & 21 & 0.012 & 0.598 & 0.15 & 0.10 & 0.06 & 0.02 & 0.15 \\
\hline
\end{tabular}

Table 10: Statistical permeability index yielded by cluster analysis in well B.

\begin{tabular}{|c|c|c|c|c|c|c|c|c|}
\hline & Number of Data & Min. & Max. & Arithmetic mean & Geometric mean & Harmonic mean & Variance & $\begin{array}{l}\text { Standard } \\
\text { Deviation }\end{array}$ \\
\hline Cluster1 & 3 & 44.989 & 80.66 & 63.16 & 61.41 & 59.65 & 318.49 & 17.84 \\
\hline Cluster2 & 10 & 11.739 & 25.42 & 16.56 & 16.14 & 15.68 & 20.38 & 4.51 \\
\hline Cluster3 & 41 & 4.572 & 9.932 & 7.29 & 7.17 & 7.05 & 1.695 & 1.30 \\
\hline Cluster4 & 33 & 0.334 & 3.657 & 1.52 & 1.20 & 0.92 & 0.92 & 0.96 \\
\hline Cluster5 & 46 & 0.248 & 3.934 & 1.47 & 1.05 & 0.75 & 1.30 & 1.14 \\
\hline Cluster6 & 13 & 0.015 & 1.398 & 0.35 & 0.19 & 0.09 & 0.17 & 0.41 \\
\hline Cluster7 & 21 & 0.029 & 2.260 & 0.32 & 0.12 & 0.07 & 0.33 & 0.58 \\
\hline
\end{tabular}

Table 11: Statistical permeability index yielded by cluster analysis in well C.

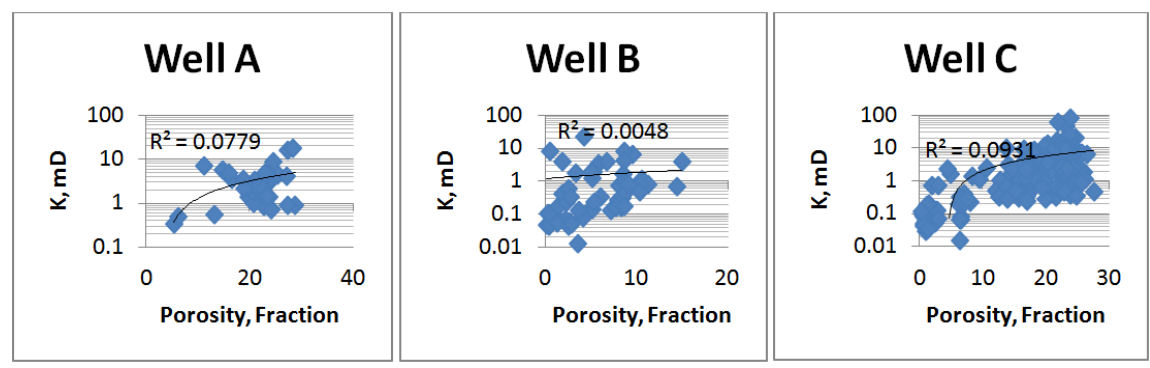

Figure 11: Porosity and permeability relation for studied wells.

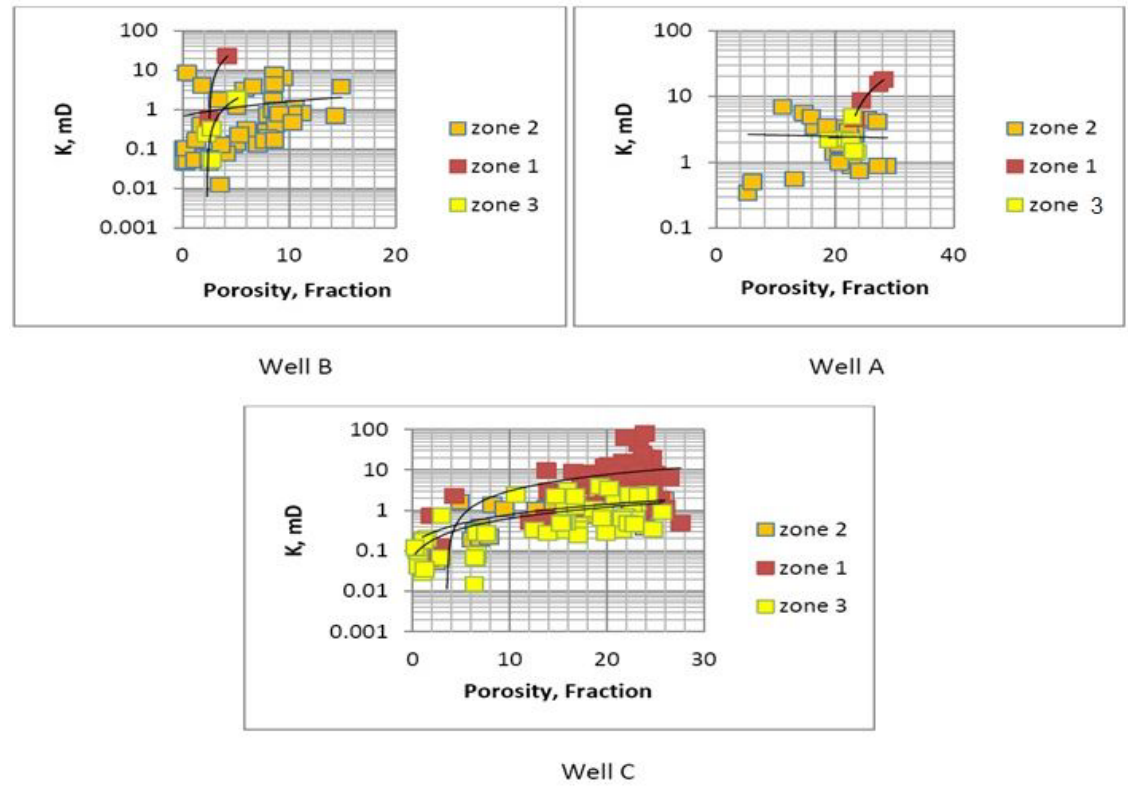

Figure 12: Relation of porosity and permeability in Testerman statistical zones. 
Citation: Mahjour SK, Al-Askari MKG, Masihi M (2015) Identification of Flow-units using Methods of Testerman Statistical Zonation, Flow Zone Index, and Cluster Analysis in Tabnaak Gas Field. J Pet Environ Biotechnol 6: 253. doi:10.4172/2157-7463.1000253

Page 10 of 13

Investigating Relation of Porosity and Permeability in Testerman Statistical Zones: Since only permeability is used for zonation in Testerman statistical method and porosity does not considered for recognition of the flow-units, therefor it is not acceptable to expect a particular relation between porosity and permeability in each of zones Figure 12.

Investigating Relation of Porosity and Permeability Inflow Zone Index (FZI) Method: Hydraulic flow-unit is a pore scale method for classification of rock types relative to flow properties based on geological parameters and flow physics. Hence relation between permeability and porosity in each hydraulic flow-unit shows a powerful correlation between these parameters Figure 13.

Investigating Relation of Porosity and Permeability in Cluster Analysis Method: Facies ordering, geological parameters and scale of pores are not considered in making clusters in grouping with cluster analysis method, albeit it is only statistical parameters and differences and similarities between permeability and porosity data which forms the groups. So data with more statistical similarities are putted in one group and there is no specific relation between porosity and permeability in each cluster, necessarily Figure 14.

\section{Transmissive Hydraulic Units (THU) and Storage Hydraulic Units (SHU)}

Identifying the units which have an important role in flow transmissivity and storage can be helpful in secondary recovery and more production of reservoir. According to acquired flow-units from different methods, this question is posed that which types of data grouping are more precise in defining transmissive and storage hydraulic units?

THU and SHU defined using Lorenz plot for porosity and permeability data [19]. THU and SHU are identifiable in intersection of tangent and unit slope to Lorenz plot, if data of each flow-unit be marked on Lorenz

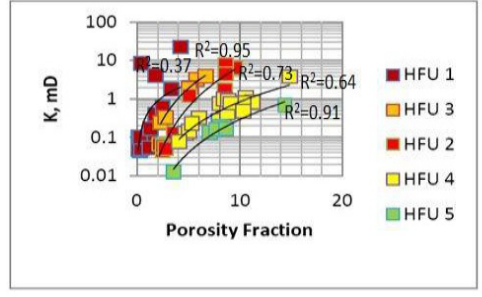

Well B

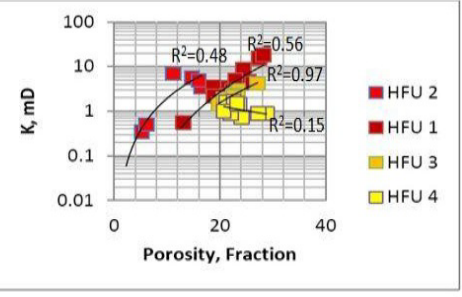

Well A

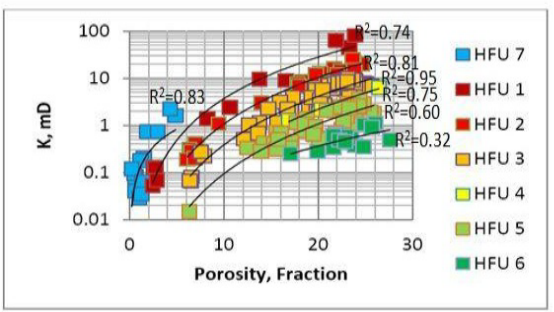

Well C

Figure 13: Relation of porosity and permeability in hydraulic flow-units.
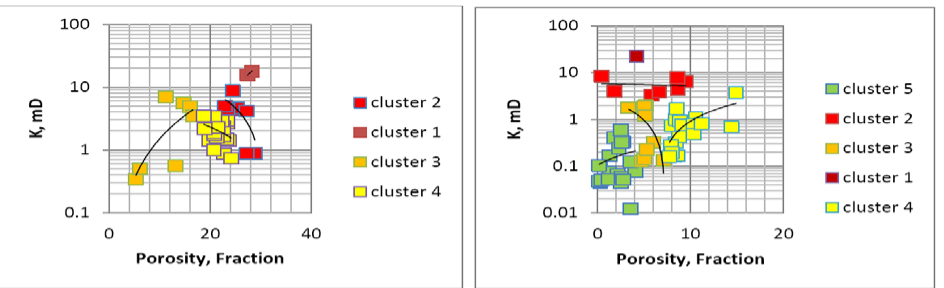

Well A

Well B

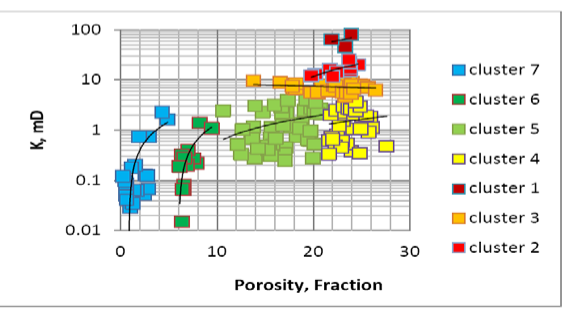

Well c

Figure 14: Relation of porosity and permeability in cluster analysis clusters. 

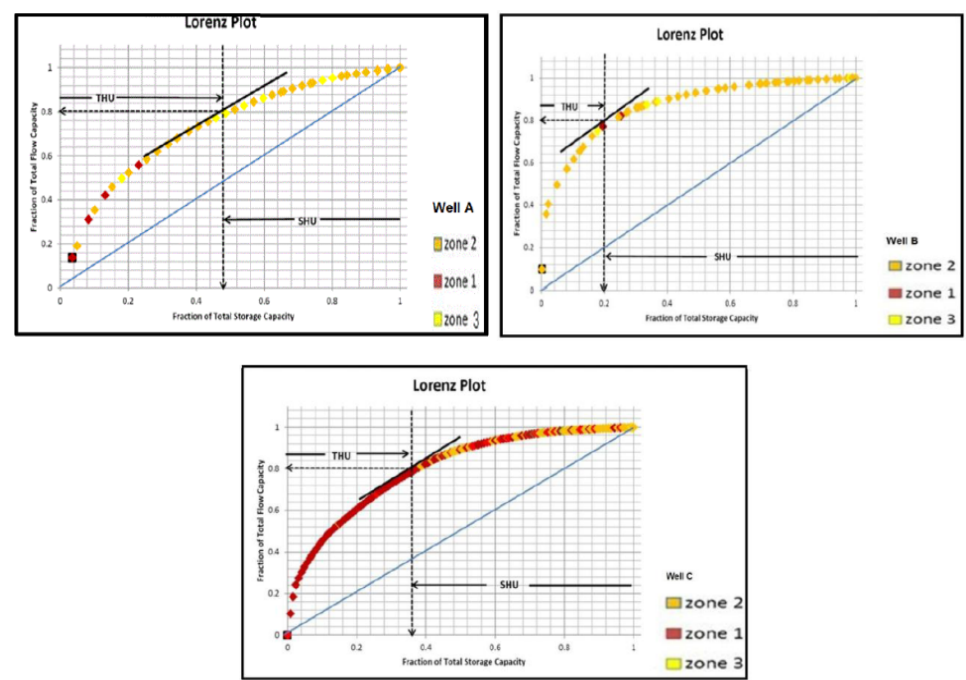

Figure 15: Identification of SHU and THU in Testerman method.

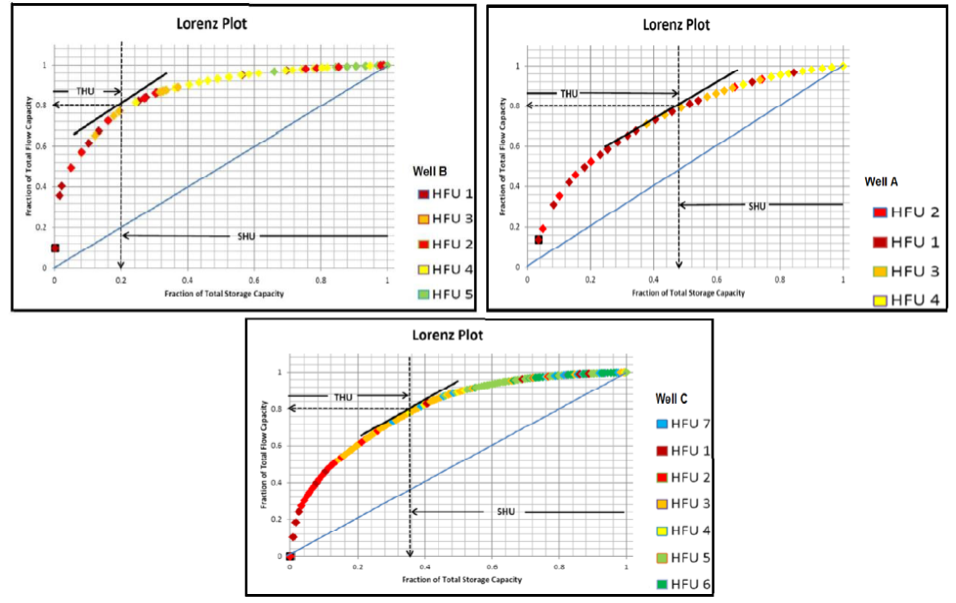

Figure 16: Identification of THU and SHU in FZI method.

plot. Now we peruse THU and SHU in different flow-units.

Identification of THU and SHU using Testerman Method: Lorenz plot of three wells is shown in Figure 15. Testerman statistical zones with different colors on diagram report that zones are scattered all over the diagram and none of them accurately specify THU and SHU. Therefore, Testerman method cannot be suitable for identification of transmissive and storage hydraulic units.

Identification of THU and SHU by FZI: Lorenz plot for three wells is shown in Figure 16. Different colored hydraulic flow-units on plot represent that unlike Testerman method, flow-units are not scattered and brightly and accurately identify THU and SHU.

Figure 16 shows that hydraulic units of 1 and 2 in well $A, 1$ and 2 in well $\mathrm{B}$, and 1 and 2 and 3 in well $\mathrm{C}$ have an substantial role on fluid transmissibility. Also hydraulic units of 3 and 4 in well A, 3 and 4 and 5 in well $\mathrm{B}$, and 4 and 5 and 6 and 7 in well $\mathrm{C}$ have important role in fluid storage.
Identification of THU and SHU by Cluster Analyzing Method: Lorenz plot for 3 wells in Figure 17 shows that in cluster analysis, clusters almost have relative concentration and have a relative accuracy for identifying Transmissiveand storage units. But accuracy in FZI method is much more than in cluster analysis.

Figure 17 shows that clusters 1 and 2 in well $A, 1$ and 2 and 3 in well $\mathrm{B}$, and 1 and 2 and 3 and 4 in well $C$ have substantial effect on fluid transmissivity. Also clusters 3 and 4 for well A, clusters 5 and 6 and 7 for well $\mathrm{B}$, and clusters 5 and 6 and 7 for well $\mathrm{C}$ have substantial effect on flow storage.

\section{Compatibility of flow-units}

Because of difference between scales of flow-units produced by different petrophysical data grouping methods, variations are obtained between them, but as Figure 18 shows accordance of defined flow units based on FZI method and cluster analysis is more than Testerman method. The reason for more compatibility in FZI method and cluster analysis is using core porosity and permeability data in identification of 


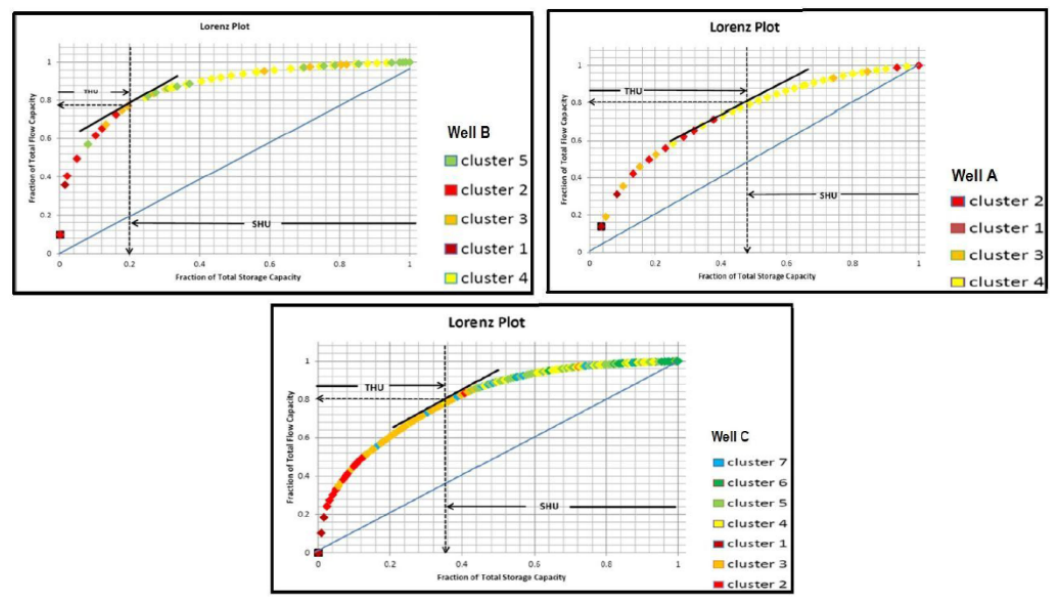

Figure 17: Identification of THU and SHU by cluster analyzing method.
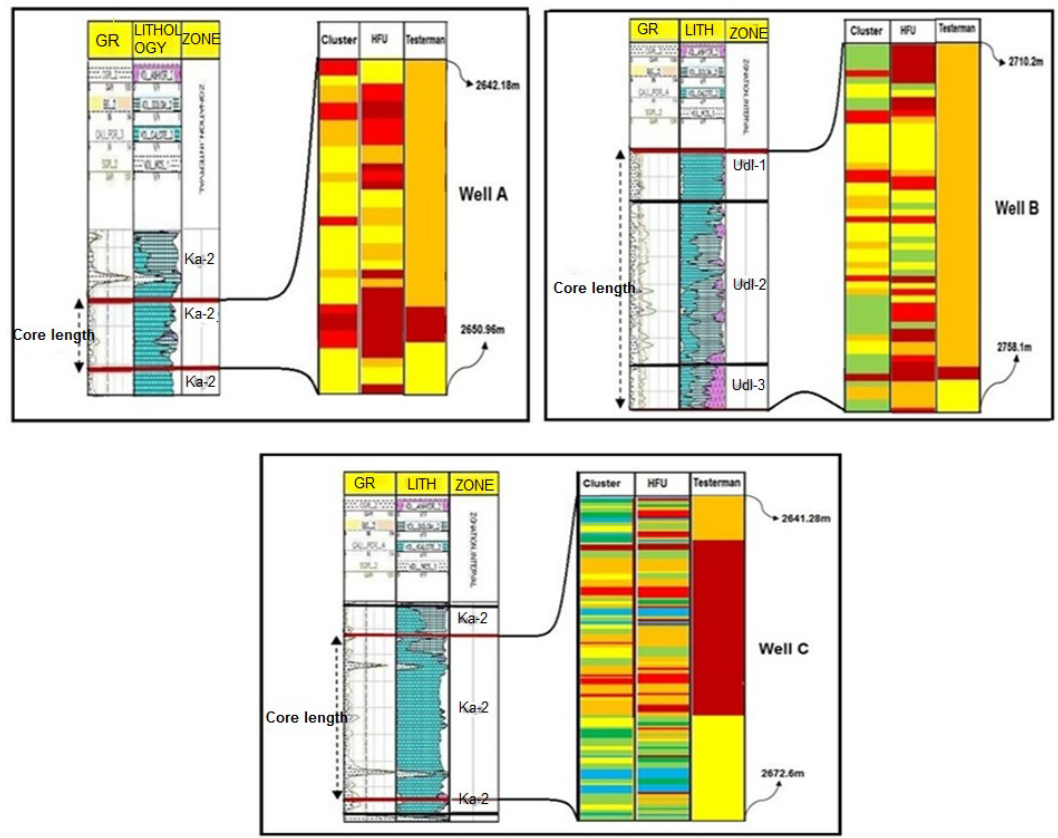

Figure 18: Accordance of flow-units in different methods.

flow-units, but in Testerman method only permeability parameters are used for this identification.

Presented flow-units with FZI and cluster analysis should be compatible in groups to being capable of reconciling between well interspaces, because detection of single flow-units in these methods is difficult and complicated. Therefor for field scale qualifying of general situation and flow interval of reservoir, applying defined flow-units based on Testerman is easier and faster.

In none of the studied techniques the facies type is not important but reserve potential of reservoir is considered, because diagenesis processes had many effects on facies so each facies can expose any porosity and permeability.

\section{Conclusions}

For identification of flow-units in Tabnaak gas field different methods have been used in this study. Comprising them yielded following results.

Using investigated methods it was understood that strong correlation between porosity and permeability only found in flow-units defined based on FZI method.

FZI and cluster analysis are preponderant for identifying THU and SHU comparing to Testerman method, in this field.

In this study it was understood that flow-units identified by FZI and cluster analysis have a relative adequate compatibility.

Compatibility and detecting a single flow-unit based on FZI and 
Citation: Mahjour SK, Al-Askari MKG, Masihi M (2015) Identification of Flow-units using Methods of Testerman Statistical Zonation, Flow Zone Index, and Cluster Analysis in Tabnaak Gas Field. J Pet Environ Biotechnol 6: 253. doi:10.4172/2157-7463.1000253

cluster analysis in field scale is difficult if not impossible. Therefor in order to characterize general situation and flow regime of reservoir in field scale, applying flow-units identified by Testerman method is easier and faster.

Only core permeability data is used in Testerman method, therefor we face more limitations for recognizing zones with more seperativity potential, and also the number of yielded flow-units is less than the two other methods.

\section{References}

1. Abbaszadeh M, Fujimoto F (1996) Permeability prediction by hydraulic flow units theory and applications, SPE Format. Evaluate 11: 263-271.

2. Shedid AS, Reyadh AA (2002) A new approach of reservoir description of carbonate reservoirs. SPE: 74344 .

3. Testerman JD (1962) A Statistical Reservoir-Zonation Technique, SPE. JPT 14: 889-893.

4. Amaefule JO, Altunbay M, Tiab D, Kersey DG, Kedan DK (1993) Enhanced reservoir description: Using core and log data toidentify hydraulic (flow) unites and predict permeability in uncored intervals / wells, SPE 26436, Texas.

5. Holland MS (2006) Cluster Analysis. Department of Geology, University of Georgia, Athens, GA 30602- 2501.

6. Insalaco E, Virgone A, Courme B, Gaillot J, Kamali MR, et al. (2006) Oil and Gas Journal. The Iranian Oil Company (NIOC).

7. Harter HL (1960) Critical Values for Duncan's New Multiple Range Test, Biometrics 16: 671 .

8. Tiab D, Donaldson EC (1996) Petrophysics: Theory and practice of measuring reservoir rock and fluid transport properties, Gulf Publishing, Houston, TX.
9. Porras JC, Barbato R, Khazen L (1999) Reservoir Flow Units: A Comparison Between Three Different Models in the Santa Barbara and Pirital Fields, North Monagas Area, Eastern Venezuela Basin. SPE 53671.

10. Tiab D, Erle C (2004) Donaldson. Petrophysics: Theory and Practice of Measuring reservoir Rock and Fluid Transport Properties. S I: Gulf Professional Publishing.

11. Ilkhchi AK, Amini A (2009) A Fuzzy logic approch To estimating hydraulic flow units from well log data: A casestudy from the Ahwaz oil field, South iran. Journal of Petroleum Geology 32: 67-78.

12. Loo B HA, Tan HTW, Kumar PP, Saw LG (2001) Intraspecific variation in Licuala glabra Griff. (Palmae) in PeninsularMalaysia a morphometric analysis. Biological Journal of the Linnean Society 72 : 115-128.

13. Castillo E, Gutierrez JM (1997) Hadi AS: Sensitivity analysis in discrete Bayesian networks, IEEE Transactions on Systems, Man and Cybernetics. 27: 412-423.

14. Xiaoling W (2009) "A Novel Circular Ring Histogram for Content-Based Image Retrieval", First International Workshop on Education Technology and Computer Science 2: 785-788.

15. Corbett PWM, Ellabad Y, Mohammed K (2001) The Recognition, Modeling and Validation of Hydraulic Units in Reservoir Rock, $3^{\text {rd }}$ Institute of Mathematics and its Applications Conference on Modelling Permeable Rocks, Cambridge.

16. Everitt B, Landau S, Leese M (2001) "Cluster Analysis”, London: Arnold.

17. Cherkassky V, Mulier FM (1998) "Learning From Data: Concepts, Theory, and Methods." New York: Wiley.

18. Intera ECL Petroleum Technologies Ltd. (1992) Marun Field study, Phase 2 Reservoir characterization, Geophysics. Intera Petroleum Production Division, Calgary, Canada.

19. Jain AK, R Dubes (1988) "Algorithms for Clustering Data", Englewood Cliffs, NJ: Prentice-Hall. 